\title{
AWARENESS, MUSCLE RELAXANTS AND BALANCED ANAESTHESIA
}

\author{
Jacob MaInzer, JR.
}

The problem of surgical pain which existed before the introduction of anaesthesia may be revisited in contemporary practice when patients experience awareness during periods of inadequate depth of anaesthesia. This spectre of fully sentient patients contradicts the humane aspirations of our specialty and the purpose of this paper is to assist in the understanding and prevention of this problem.

Reviews dealing with the complication of awareness have been published ${ }^{1-10}$ and attention has also been directed towards this problem by four decades of editorials. ${ }^{1-25}$ Unintentional awareness is usually related to the injudicious use of muscle relaxants, the use of anaesthetic agents which either alone or in combination are not entirely amnesic or analgesic and the use of the lightest possible levels of anaesthesia.

\section{HISTORICAL ASPECTS}

A wareness and pain due to insufficient anaesthesia were recognized as early as $1847 .{ }^{26} \mathrm{Ex}$ perimental work by Claude Bernard ${ }^{27.28}$ encompassed both the muscle relaxants and balanced anaesthesia. He identified the neuromuscular junction as the site of action of curare and he also introduced the practice of using more than one anaesthetic agent at a time. He called this technique "mixed anaesthesia" and reported that morphine decreases both the amount of chloroform need for anaesthesia and its duration.

Curare continued to be used in animal experiments and, since most scientists felt that it did not affect consciousness, its use caused considerable antivivisectionist fervour during the last half of the nineleenth century. Such sentiments were reflected in an 1880 Tennyson poem condemning the "hellish oorali". 28

It was not until 1896, however, that William Welch" in his "50th Ether Day" anniversary

Jacob Mainzer, Jr., M.D., Staff Anaesthesiologist, Presbyterian Medical Center. Albuquerque, New Mexico: Lecturer, Anesthesiology and History of Medicine. University of New Mexico School of Medicine.

Author's Address: 2117 Menaul N.E., Albuquerque, N.M. 87107 . U.S.A. 386 lecture suggested that curare might be safely used with anaesthelics in man. In 1912, Arthut Lawen used curare ${ }^{30}$ as an aid to anaesthesia, but it was not unti] 1942 that Griffith and Johnson's cautious demonstration of the benefit of curare ${ }^{31}$ paved the way for its wide acceptance in medicine.

Reports of the use of curare as the sole agent in anaesthesia followed, ${ }^{32-35}$ with only some of the patients complaining postoperatively of awareness with pain. ${ }^{35}$ Thus the debate concerning the effect of curare on consciousness in man was briefly renewed until two fearless investigators, Prescott ${ }^{36}$ and Smith $^{37}$ by experimenting upon thenselves, showed that it had no such effect in clinical doses. They amplified the warning of a 1945 Lancet editorial'2 that, when using curare, "we must ensure unconsciousness".

Although a patient of Crile's ${ }^{38}$ in 1908 experienced awareness during nitrous oxide anaesthesia, it was Winterbottom's 1950 case report ${ }^{39}$ that widely publicized the possibility of awareness and pain during operations. In 1951, Mushin ${ }^{40}$ reported another case, and he was " inclined to believe that this occurrence may be more common than we think".

In 1956 Fairley ${ }^{41}$ reported a 30 per cent incidence of recall during anaesthesia for endoscopy and in 1957 Frumin $^{42}$ reported that of 171 patients, nine experienced awareness, three had pain, many had dreams and that on five occasions succinylcholine apnoea had outlasted the operation. Since then frequent case reports have appeared in the correspondence sections of medical journals relating episodes experienced personally.

\section{Balanced Anaesthesia}

The balanced anaesthesia technique with paralysis has almost eliminated the ability to appreciate anaesthetic depth ${ }^{43-46}$ and even a gross change, such as awakening or over-dosage, can remain undetected, as the guidelines for drug administration may largely be derived from pre-set criteria unrelated to the particular patient being treated.

A wareness can occur when a patient drifts into the light planes of amnesia-analgesia, which 
characterize stage I depth. Paradoxically, the surgeon's responses about the degree of "relaxation" "may often be used to help judge the depth of "anaesthesia".

At times the agents in balanced anaesthesia counteract each other's undesired effects, as noted in the ability of curare to depress the circulatory stimulant properties of ketamine, ${ }^{47}$ Conversely, the components may also work at cross-purposes, as the anti-analgesic activity of thiopentone and analgesic properties of the opiates and nitrous oxide. ${ }^{48}$ The routine use of reversal agents (physostigmine, narcotic antagonists, anticholinesterases, and analeptics) in balanced techniques introduces special additional drug problems into the operative and recovery care of these patients.

Individual chronic tolerance to barbiturates, narcotics and ketamine is well known and $\mathrm{Sia}^{49}$ felt that previous exposure to anaesthetics induces a tolerance which was responsible for a higher incidence of awareness in re-anaesthetized patients. Cross tolerance between chronic alcohol exposure and anaesthetics has also been demonstrated ${ }^{50}$ necessitating a need for more anaesthetic in such patients. Though increased drug tolerance may weaken the expected potency of an anaesthetic, no similar evidence of habituation or tolerance to pain exists ${ }^{51}$ to counterbalance such diminished drug effectiveness and help prevent awareness in these cases.

\section{STUdIES OF AWARENESS}

Frumin $^{42}$ reported five per cent incidence of awareness, and Hutchison ${ }^{3}$ established the incidence at one per cent in her series. A recent editorial stated that the range varied between none to 25 per cent. ${ }^{23}$

Bergstrom and Bernstein's ${ }^{52}$ experience in caesarean section patients was even more varied with a 100 per cent incidence of nightmares during anaesthesia in six patients with their "method $A$ ", and no reactions in 11 patients with "method B". Crawford in his caesarean section series ${ }^{53}$ reported an incidence of awareness of three per cent. Both $\mathrm{Ng}^{54}$ and Crawford ${ }^{\mathrm{s}}$ reported that some caesarean patients have had more than one episode of awareness during anacsthesia.

In general surgery, Wilson ${ }^{5 s}$ found a one per cent incidence of awareness and reported no correlation to either the type of operation, duration of anaesthesia or patient age. In a larger series of 4,000 patients, Lett ${ }^{56}$ also reported a one per cent overall incidence with a higher frequency in patients undergoing endoscopy, caesarean section and biliary surgery. Fairley, ${ }^{41}$ Barr $^{57}$ and McKenna ${ }^{58}$ similarly reported a higher incidence of awareness during endoscopy and tracheal intubation.

Mendelsohn"s9 had "several" cardiac surgery patients in a series of 58 patient report awareness. but a lack of fear or discomfort. Lowenstein ${ }^{24}$ found that despite total analgesia. consciousness during anaesthesia was a problem and Maunuksela ${ }^{60}$ in his cardiac patients noted awareness was more common in those who were younger, in better physical condition, and who had received balanced or neurolept anaesthesia rather than halothane.

In a prospective study of awareness Authier ${ }^{61}$ showed that amnesia during surgery was greater in subjects uninformed of the study than in those informed beforehand. Many prospective studies have found that awareness did not occur. ${ }^{7.62-66}$ This may be due to more meticulous attention to the depth of anaesthesia during the study.

Cobb' ${ }^{11}$. Frumin ${ }^{42}$ and Smith $^{34}$ all expressed concern about untoward psychological consequences of awareness during paralysis, but were unable to provide definitive follow-up data. Meyer and Blacher ${ }^{68}$ and Blacher ${ }^{69}$ in studies of eleven patients, described a traumatic neurosis (catastrophe reaction) in response to awakening while paralyzed during surgery although they did not necessarily feel pain. They felt that relief of symptoms could be obtained in these patients by sympathetically explaining exactly what had happened during the operation, and they recommended this as therapy for such patients, taking care to discuss any mitigating factors, such as an arrhythmia or shock. In a follow-up correspondence to Blacher's ${ }^{69}$ report, Larson ${ }^{70}$ disputed some of his broad and theoretical interpretations. The many reports of personal awareness experienced by physicians, ${ }^{19.36,37}$ suggest that professional knowledge does not mitigate the discomfort of awareness while paralyzed.

Studies using hypnosis have suggested that recall is not only possible but likely under even deep general anaesthesia ${ }^{71.32}$. Other reports deny this, ${ }^{62-66.73}$ and the problem of auditory perception during general anaesthesia has been reviewed, ${ }^{74}$ with the recommendation for better designed and controlled studies.

Although the illegal use of anaesthetics, and especially relaxants, in awake victims ${ }^{75}$, has been well publicized in the popular media, the legal status of awareness during surgery is uncertain. It would seem to be one of the risks of the safe 
practice of medicine and. as one editor ${ }^{20}$ concludes. "assessing the state of consciousness of the paralyzed patient is something on which even the most experienced may occasionally be deceived".

\section{Classification of Periods of Awareness During Paralysis}

\section{Preoperative period}

The use of non-depolarizing relaxants to diminish undesirable effects of succinylcholine is widely practiced and reported to be "harmless and comfortable ${ }^{" 76}$. Similar low dosage has been advocated as an aid to operntions under local anaesthesia, ${ }^{77}$ but this is condemned by other $s^{78}$ as unsafe and uncomfortable.

\section{Intubation period}

Awake intubation for emergency operations is an accepted technique. ${ }^{79}$ but awareness during intubation in elective operations is also often reported. especially when difficulty is encountered. so that the relaxant outlasts the induction agent. ${ }^{58}$ Beyond the problem of recall. light anaesthesia at this time can expose the patient to serious vascular complications from the pressor response to intubation. ${ }^{\text {so }}$

\section{Intraoperative period}

Recall at this time may35,39,67.81 or may not ${ }^{40.44 .54,82}$ be accompanied by pain. It can also be associated with pleasant or unpleasant dreams and may occur as a dissociative "out of body" phenomenon. ${ }^{5}$ Recall may also be due to the very light antesthesia deliberately maintained because of concern for cardiovascular stability or for the unborn child of an unpremedicated mother undergoing caesarean section. Brief awakening from anaesthesia during Harrington rod instrumentation seems to be painless, as the patients are advised of the plan preoperatively and also as a result of the precaution that no manipulations or new incisions are carried out during this period of awareness. ${ }^{83}$ Neuro-surgical experience 16 has been similarly reported as comfortable where consciousness was a requirement of the surgical technique.

\section{Postoperative period}

Awareness may occur if the relaxant outlasts the operation and anaesthesia is discontinued. Maintenance of nitrous oxide is often recommended therefore until reversal has occurred. Potential postoperative awareness may be antici- pated before completion of the operation as in suspected cholinesterase deficiencies or in the myasthenic syndrome. Reassurance together with appropriate sedation can be given, while ventilation is being supported.

\section{Periods of extra-strgical recall}

Use of relaxants. alone or with inadequate sedation, in coronary and intensive care units often results in unpleasant and frightening recall of cardioversion, tracheal intubation, or induced paralysis to prevent "fighting the ventilator". 19

\section{CAse Reports}

All cases except the last accurred at an altitude of approximately 5,000 feet at an ambient pressure of $83.79 \mathrm{kPa}(630 \mathrm{~mm} \mathrm{Hg})$. A study of nitrous oxide anaesthesia at this altitude described recall in one of 14 patients. $^{82}$

\section{Preoperative period}

Uncomfortable experiences after pretreatment with low doses of curare were seen chiefly in our caesarean section patients who usually complained of shortness of breath despite inhalation of oxygen. Agitation was seen in a teenage spastic child who was to undergo eye surgery and who found the motor impairment disagreeable.

\section{I. Intubation period}

Two cases of awareness and discomfort during intubation were seen in young women aged 19 and 24 . In one the intravenous line was lost just after induction, delaying supplementation. Both communicated their complaints directly to the anaesthetist after discharge from hospital.

\section{During operation}

Recall with pain was seen in the following cases:

1. A 37-year-old woman had meperidine $100 \mathrm{mg}$ with hyoscine $0.3 \mathrm{mg}$ for premedication. This was followed by thiopentone $300 \mathrm{mg}$, alphaprodine 36 $\mathrm{mg}$ and pancuronium $6 \mathrm{mg}$. with 50 per cent nitrous oxide and oxygen for a 90 -minute cholecystectomy. Recovery was uneventful. Three years later on admission for further surgery, she complained bitterly of awakening twice during the earlier operation in great pain and unable to move or talk. After the second anaesthetic, identical to the first except for the addition of enflurane up to two per cent, no recall could be elicited.

2. A 53-year-old man, a reformed alcoholic taking chlordiazepoxide $100 \mathrm{mg}$ daily received 
$300 \mathrm{mg}$ thiopentone followed by diazepam $10 \mathrm{mg}$. morphine $15 \mathrm{mg}$. fentanyl $0.2 \mathrm{mg}$ and curare 87 mg with 67 percent nilrous oxide for a 200-minute gastric operation. He complained of painful awareness and his postoperative narcotic requirements were high. His wife, on a surgical admission later. refused to have his anaesthetist for her operation.

3. A 41-year-old woman received meperidine $75 \mathrm{mg}$ for premedication, thiopentone $\mathbf{2 0 0} \mathrm{mg}$ for induction, and meperidine $60 \mathrm{mg}$, pancuronium 7 mg. with 67 per cent nitrous oxide in oxygen for maintenance during a two-hour pelvic operation. Anaesthesiat was unremarkable, with cardiovascular stability. Three weeks after the operation her husband contacted the anaesthetists about her recall of excruciating pain and total "helpless" paralysis during the operation, together with recurrent nightmares postoperatively. He declined to allow her to be interviewed. but the surgeon later related that the night terrors had slowly disappeared.

4. A 48-year-old man received morphine $10 \mathrm{mg}$ and hydroxyzine $50 \mathrm{mg}$ for premedication, thiopentone $500 \mathrm{mg}$ for induction and meperidine $120 \mathrm{mg}$. curare $54 \mathrm{mg}$ with 67 per cent nitrous oxide in oxygen for maintenance in the course of a two-hour cholecystectomy. Several days postoperatively he told his surgeon he had experienced pain and awareness.

5. A 65-year-old woman received unsupplemented thiopentone. curare, with 67 per cent nitrous oxide in oxygen during which she experienced surgical atwareness and pain.

6. A SI-year-old woman had a shoulder repair under balanced technique and experienced excruciating pain and exact conversational recall. She refused to return to that same hospital for two later operations.

7. A 58-year-old man who weighed $90 \mathrm{~kg} \mathrm{had}$ diazepam $20 \mathrm{mg}$, curare $27 \mathrm{mg}$. gallamine $120 \mathrm{mg}$. morphine $275 \mathrm{mg}$ and 50 per cent nitrous oxide in oxygen for a five-hour repair of atrial septal defect using the bypass pump oxygenator. He experienced operative awareness and pain. Postoperatively he required additional sedation because of "tenseness" and he refused to lie down. preferring only to sit up in bed during convalescence.

Three patients experienced awareness during operation under general anaesthesia without feeling pain.

8. A 47-year-old man who had multiple vascu- lar operations for advanced athero-arteriosclerosis was aware of the operation but free of pain during a period of hypotension when the anaesthetic was briefly stopped.

9. A 41-year-old woman experienced awareness fwice without pain during an abdominal operation under balanced technique. Over-hearing the conversation she recalled wondering if tying of the requested retention sutures would hurt. but she fell asleep again.

10. After a laminectomy a 50-year-old woman recalled explicit surgical directions which she could otherwise not have known, such as "Put the pieces of the disc into the medicine glass". She had no pain or discomfort and said she seemed to be out of her body and present only peripherally as an uninvolved observer.

Recall during periods of inadvertent administration of muscle relaxamts without anaesthesiat

11. A surgeon as was his routine for extensive procedures using local anaesthesia. started an intravenous infusion on a 26-year-old woman. He used a bottle left hanging on the intravenous standard. Twitching and convulsive agitation of the patient became "unresponsive" respiratory depression, which was quickly treated by an immediately available anaesthetist. The bottle contained 0.2 per cent succinylcholine and was so labelled in small writing.

12. A 31-year-old woman who was waiting for anaesthesia to be started, received $40 \mathrm{mg}$ of succinylcholine slowly intravenously when the intravenous "piggyback" line, inserted as a relaxant drip for later use, had been incompletely clamped shut. Immediate diagnosis and treatment was successful, but on returning for another operation one year later. she requested no more "funny anaesthesia".

13. In a case similar to the two above, a pitient was thought to have been given alphaprodine 12 $\mathrm{mg}$ intravenously before induction. but in fact received succiny lcholine $20 \mathrm{mg}$.

14. A 26-year-old female had a negative surgical exploration at midnight for a penetrating stab wound of the abdomen. The primary anaesthetic was cyclopropane with a drip infusion of succinylcholine. She awoke very quickly, was coherent, had stable vital signs and was discharged to the ward. Three hours postoperatively her condition was satisfactory. Some time thereafter she received the $300 \mathrm{ml}$ of fluid left in a bottle attached as a "piggyback" intravenous. She was found dead two hours later, and the "piggyback" bot- 
tle, labelled succinylcholine. was empty. Awareness was presumed to have occurred.

\section{Prevention}

Since no adequate sign or test of awareness during anaesthesia exists, both diagnosis and prevention are difficult. Most suggestions for prevention or correction relate to deepening of the anaesthetic, $11,12.21-23.40$ unless the patient's condition is so precarious as to exclude supplementation.

Crawford ${ }^{53}$ in extensive studies of awareness in caesarean section patients, recommends the addition of low concentrations of volatile agents after delivery, while others ${ }^{84,85}$ recommend them as a preventative from the time of induction. Premedication is similarly regarded ${ }^{86}$ and nar$\operatorname{cotics}^{54}$ or thiopentone ${ }^{22}$ after delivery are also recommended.

Muscle relaxants should be used cautiously and only when necessary. If paralysis is partial the patient may be able to respond effectively if awareness occurs. Dundee ${ }^{87}$ has shown that narcotic supplementation allows for reduction in the dosage of relaxant.

The routine electroencephalogram has not lived up to expectation as a reliable guide to the assessment of anaesthetic depth during operation. ${ }^{43} \mathrm{~A}$ different recording technique has recently allowed for the study of circulatory and respiratory effects of the electroencephalographically detected arousal response and it was felt that this could be of value in detecting awareness.8s In a similar way, the electroencephalograph cerebral function monitor has had success in detecting both light and deep anaesthesia and hypoxia. ${ }^{89}$ Monitoring of galvanic skin response is also suggested as a guide to arousal and awakening. ${ }^{90}$

A digital pulse volume plethysmograph can demonstrate vasoconstriction indicating inadequate anaesthesia. Vasodilatation is regarded as a sign of unconsciousness in patients lightly anaesthetized with halothane. ${ }^{91}$ This correlates with findings that 0.65 per cent halothane added to nitrous oxide and oxygen in caesarean section patients prevents awareness ${ }^{\mathrm{ks}}$ and that pallor and clinical vasoconstriction are indications for narcotic supplementation. ${ }^{87}$

Tunstal $1^{92}$ devised a simple technique for detecting awareness during anaesthesia. A blood pressure cuff inflated above the systolic pressure isolates one arm from the general circulation before induction. The patient can then move that arm in response to pain and questioning after induction, if he is conscious, as the arm has had no exposure to relaxants. The usual time-limits for maintenance of an ischaemic limb must be adhered to.

"Minimum blood concentration" has been proposed as a guide to anaesthetic depth and potency. ${ }^{93}$ However, studies of the awakening level of thiobarbiturates show wide variations. ${ }^{94}$ Continuous or intermittent determinations of andesthetic concentrations moreover are not widely available for either exhaled air or blood.

Although clinical signs of impending consciousness are neither consistent nor reliable. some of the following may be seen: decreased compliance, bronchospasm, tracheal tug. swallowing, sweating, lacrimation, changes in blood pressure, pulse or pupil size and facial, eye or other movements. A relationship was shown between dreaming and movement during surgery. ${ }^{73}$ However, the most purposeful movements often are associated with the least awareness. ${ }^{40.41}$ Fairley ${ }^{41}$ reported little relationship between suspected and actual awareness in any particular case.

The possibility of auditory perception ${ }^{74}$ during anaesthesia requires that all operating-room conversation receive our most thoughtful consideration. ${ }^{5,7,57,71.72}$ Ear plugs for patients and distracting music have been recommended. However, if not directly for patient reassurance during awareness, then for the sake of the attitude of the surgical team, all conversation about the patient should be both optimistic and supportive.

Finally, in the prevention of awareness, the importance of meticulous attention to the details of the technique must be re-emphasized ${ }^{45}$ so that the patient may be assured of safety and comfort.

\section{SUMmary}

The incidence of awareness during insufficient anaesthesia is reported to be one per cent. It is usually due to the use of muscle relaxants, a balanced technique and the lightest possible depth of anaesthesia. Increased incidences were noted in open-heart surgery, during intubationendoscopy procedures and in caesarean delivery patients.

Experiences of awareness are disturbing to patients, who are usually benefited by a sympathetic and forthright explanation of the event. Fourteen representative cases of the problem are reported.

Since no adequate sign or test exists for detec- 
tion of awareness during very light anaesthesia or with associated paralysis, more meticulous attention is required in using relaxants or the balanced technique. Greater anaesthetic supplementation and reduction in the use of relaxants are recommended to halt the recurrence of this most serious anaesthetic problem.

\section{RÉSUMÉ}

Le maintien de la conscience au cours d'anesthèsies de profondeur insuffisante est de l'ordre d'un pourcent. Cette complication survient le plus souvent avec les techniques d'anesthésie balancéc alors que l'on utilise des curarisants tout en maintenant le niveau d’anesthésie le plus léger possible. Les situations où l'on est le plus susceptible de rencontrer le phénomène sont le moment de l'intubation endotrachéale et les procédures endoscopiques en général, ainsi que la chirurgie cardiaque et les accouchements par césarienne.

C'est une expérience traumatique pour les malades. 11 est généralement préférable de leur fournir une explication franche du phénomène tout en adoptant une attitude sympathique.

Comme il n'existe pas de signes permettant de détecter que l'état de conscience persiste au cours d'anesthésie légère avec curarisation, il faut être très conscient de ce danger, et utiliser les curares et l'anesthésie balancée avec grande attention. Il est recommandable d'utiliser une anesthésie plus profonde et moins de relaxants musculaires afin d'éliminer ce problème sérieux.

Les auteurs rapportent quatorze cas du genre pour illustrer leur présentation.

\section{REFERENCES}

I. Cherkin, A. \& Harroun, P. Anesthesia and memory processes. Anesthesiology 34: 469 (1971).

2. Holmes, C.M. "Perchance to Dream": the paradox of awareness during general anaesthesia. Austral. N.Z. J. Surg. 40:200 (1970).

3. Hutchinson, R. Awareness during surgery. Br. J. Anaesth. 33: 463 (1961).

4. MCINTYRE. J.W.R. Awareness during general anesthesia: preliminary observations. Canad. A naesth. Soc. J. 13: 495 (1966).

5. Mostert, J.W. States of awareness during general anesthesia. Perspectives Biol. Med. 18: 68 (1975).

6. Parkhouse, J. A wareness during surgery. Postgrad. Med. J. 421: 674 (1960).

7. ScorT. D.L. Awareness during general anesthesia. Canad. Anaesth. Soc. J. 19: 173 (1972).

8. Stephen. C.R. Clinical Anesthesia Series 1968 , \#3. pp. I13-119. A wareness during anesthesia.

9. UTTING. J.E. A wareness in anaesthesia. Anaesth. Intens. Care 3: 334 (1975).
10. Waters. D.J. Factors causing awareness during surgery. Br. J. Anaesth. 40: 259 (1968).

11. Cose. S. Editorial. Muscle relaxants and pain perception. Anesthesiology $22: 314$ (1961).

12. Editorial: Curare in anaesthesia. Lancet 2: 81 (1945).

13. Editorial: Consciousness during surgical operalions. Br. Med. J. 2: 810 (1959)

14. Editorial: "Levels" of anaesthesia. Lancet $I: 95$ (1961).

15. Editorial: Awareness during surgery, Lancet 2: 1394 (1961).

16. Editorial: Is the anaesthetic really necessary? Lancet /: 1043 (1967).

17. Editorial: Awareness during an operation. Lancet I: 1188 (1968)

18. Editoriat: Half an anaesthetic, Lancet 1 : 1137 (1969).

19. Editorial: The other end of the stick. J.A.M.A. 210: 896 (1969).

20. Editorial: Awareness during anaest hesia. Lancet 2: 1305 (1973).

21. Editorial: Anguish unremembered. Lancet 1: 968 (1974).

22. Editorial: Awareness during general anaesthesia. Med. J. Austral. 2: 765 (1974).

23. Editorial: Awareness during anaesthesia. Br. Med. J. 2: 977 (1976).

24. Lowenstein, E. Editorial: Morphine "anesthesia". a perspective. Anesthesiology 35: 563 (1971).

25. LUNN, J.N. Editorial. Aniesthesia 33: 131 (1978).

26. Lancet. Operations without pain. $I: 77$ (1847).

27. LEE. J.A. Claude Bernard (1813-1878). Anacsthesia $33: 741$ (1978).

28. STEVENSON, L.G. The meaning of poison. University of Kansas Press, Lawrence. pp. 23-45. "Hellish Oorali" (1959).

29. WelCH. W.H. The influence of anesthesia upon medical science. Boston Med. Surg. J. (N. E.J.M.) $85: 401(1896)$

30. Läwen. A. (1912) in Faulconer. A. \& Keys T.E. Foundations of anesthesiology. Springfield. III. C.C. Thomas. pp. 1183- I 186 (1965).

31. Griffith, H.R. \& Johnson, G.E. The use of cu rare in general anesthesia. Anesthesiology 3: 418 (1942).

32. BURN. J.M.B. Relaxant anaesthesia for abdominal operations using hyperventilation with air. Anaesthesia 18:84 (1963).

33. Gill.is, A. \& Webster. D.D. D-Tubocurarine chloride in electroconvulsion therapy. $\mathrm{Br}$. Med. J. l: 451 (1947).

34. Sмiтн, S.M. The use of curare in infants and children. Anesthesiology 8: 176 (1947).

35. Whitacre. R.J. \& Fisher, A.J. Clinical observations on the use of curare in anesthesiology. Anesthesiology 6: 124 (1945).

36. Prescott. F.. Organe. G. \& Rothbotham. S. Tubocurarine chloride as an adjunct to anaesthesia. Lancet 2: 80 (1946).

37. SMith, S.M., BRown. H.O. TOMan, J.E.P. \& Goodman, L.S. The lack of cerebral effects of d-tubocurarine. Anesthesiology $8: 1$ (1947).

38. Crile, G. George Crile, An Autobiography. Philadelphia, Lippincott. p. 197 (1947). 
39. WINTERBOTtom. E.H. Correspondence. Insufficient atnaesthesia. Br. Med. J. I: 247 (1950).

40. Mushin, W.W. Analgesics as supplements during ancesthesia. Proc. Roy. Soc. Med. 44: 840 (195I).

41. FairL.EY. H.B. An evaluation of local and general tincesthesial for diagnostic brochoscopy. Canad. Anaesth. Soc. J. 3: 366 (1956).

42. Frumin. J.J. Clinical use of a physiological respirattor producing $\mathrm{N}_{2} \mathrm{O}$ amnesia-analgesia. Anesthesiology 18: 290 (1957).

43. ROSNER. B.S. \& ClARK. D.C. Neurophysiologic effects of general anesthetics. Anesthesiology 38: 564 (1973).

44. LUNDY, J.S. Balanced Anesthesia. Minnesola Med. 9:399(1926)

45. Cascorbi, H.F. \& Gravenstein, J.S. Editorial. Silent death. Anesthesiology 40:319 (1974).

46. ADR1ANI. J. Editorial, Balanced anesthesia. Survey Anesth. 3: 625 (1959).

47. SAvigl. T.M. Colvin. M.P.. Weaver. E.J.N., Bond, C.. DRAKE. J. \& INNISS. R. A comparison of some cardiorespiratory effects of althesin and ketamine. Br. J. Anaesth. 48: 1071 ( (1976).

48. Clutron-Brock. J. Pain and the barbiturates. Anaesthesiat 16: 80 (1961).

49. SiA. R.L. Consciousness during general anesthesia. Anesth. Analg. 48: 363 (1969).

50. Tammisto. T. \& Tigerstedr. I. The need for fentinyl supplementation of nitrous oxide-oxygen-relaxant anesthesia in chronic alcoholism. Acta Antiesth. Scand. 21:216 (1977).

51. ClutTON-Brock. J. Some aspects of the problem of consciousness and anilesthesia. Anaesthesia 19: 115 (1964).

52. Bergström, H. and Bernstein, K. Psychic reactions after analgesia with nitrous oxide for cesarean section. Lancet 2: 541 (1968).

53. CRAwford, J.S. Awareness during operative obstetrics under general anaesthesia. Br. J. Anaesth. 43: 179 (1971).

54. NG. K.H. \& Gurubatham, A.I. Awareness duling cesarean section under general anesthesia. Med. J. Austral. 2: 774 (1974).

55. Wilson, S.L. Vaughn. R.W. \& Stephen, C.R. Awareness. dreams and hallucinations associated with general anesthesia. Anesth. Analg. 54: 609 (1975).

56. LETT, $Z$. A wareness and pain during general anesthesia. Proceedings. Fourth World Congress of Anesthesiology. Exerpta Medical Foundation. Amsterdam, pp. 538-54l (1970).

57. BARK. A.M. \& Wong. R.M. Awareness duing general anaesthesia for bronchoscopy and laryngoscopy. Br. J. Anaesth. 45: 894 (1973).

58. MCKEnNa, T. \& Wilton, T.N.P. Awareness during endotracheal intubation. Anaesthesia 28: 599 (1973).

59. Mendelsohn, D. Macdonald, D.W. NoGUEIRA.C. \& KAY. E.B. Anesthesia for open-heart surgery. Anesth. Analg. 39: 110 (1960).

60. Maunuksela, E-L. Hemodynamic responses to different anesthetics during open-heart surgery. Acta Anaesth. Scandin. Suppl. 65: 43 (1977).

61. Authier. L.. Rousseau. P.. Paquin, P., OuelLETTE, M. Taillefer. J., Jobin, D. et Barry. P.P. Amnésie de mémoration post-anesthésique. Canad. Anaesth. Soc. J. 21:46 (1974).
62. Agarwal. G. \& Sikn. S.S. A witreness duting anaesthesia, a prospective study. Br. J. Anaesth. 49: 835 (1977)

63. Dubovsky, E.L. \& Trustaman. R. Absence of recall after general anesthesia. Anesth. Analg. 55; 696 (1976)

64. Eisele. V.. Weinreich, A. \& Bartl.i. S. Perioperative awareness and recall. Anesth. Analg. $55: 513$ (1976).

65. Terrell. R.K.. Sweet. W.O.. Gladphit th.r. J.H. \& STEPHEN. C.R. A study of recall during anesthesia. Anesth. Analg. 48: 86(1969).

66. WILSON. J.. LEWIS. S.A. \& JIENKINSON, J.L. Electroencephalographic investigation of awareness during anaesthesia. Br. J. Anaesth. 42: 804 (1970).

67. Gordh. T. \& Mostert. J.W. Anesthetic accidents, case studies. Internat. Anesth. Clin. 16: $77-80$ and $152-154$ (1978).

68. Meyer. B.C. \& Blancher. R.S. A triumatic neurotic reaction induced by succinylcholine. N.Y. State J. Med. 6I: 1255 (1961).

69. BlACHER, R.S. On awakening paralyzed during surgery, a syndrome of traumatic neurosis. J.A.M.A. 234: 67 (1975)

70. LARSON. C.P. Letters, On awakening paralyzed during surgery. J.A.M.A. 235: 1209 (1976).

71. Cheex, D.B. Can surgical patients react to what they hear under anesthesia? J. Am. A. Nurse Anesth. 33: 30 ( 1965).

72. LEVINSON. B.W. States of awareness during general anaesthesia. Br. J. Anaesth. 37: 544 (1965).

73. Brice. D.D., Hetherington. R.R. \& UTiting, J.E. A simple study of twareness and dreaming during anaesthesia. Br. J. Anaesth. 42: 535 (1970).

74. Trustman, R. Dubovsky, S. \& Titley. R. Al ditory perception during general anesthesia. Internat. J. Clin. Exp. Hyp. 25: 88 (1977).

75. Maltby, J,R. Criminal use of anaesthetic drugs. Anaesthesia $32: 212$ (1977).

76. DERY, $R$. The effects of precurarization with a protective dose of $\mathrm{d}$-tubocurarine in the conscious patient. Canad. Anzesth. Soc. J. 2l: 68 (1974).

77. Bharksuwana, E. \& Maher. W.J. Curte, an aid in surgery of cataract. Bull. N.Y. Acad. Med. 52: 212 (1976)

78. Feldman, S.A. Comments. Survey Anesth. 20: 445 (1976).

79. DUNCAN, J.A.T. Intubation of the trachea in the conscious patient. Br. J. Anaesth. 49:619 (1977).

80. Fox, E.J., Sklar, G.S., Hill., C.H., VIlLANUEVA, R. \& Kings, B.P. Complications related to the pressor response to endotracheal intubation. Anesthesiology 47: 524 (1977)

81. GrafF. T.D. \& Phillips. O.C. Consciousness and pain during apparent surgical anesthesia. J.A.M.A. 170: 2069 (1959).

82. Powell, J.N. \& Gingrich. T.F. Some aspects of nitrous oxide anesthesia at an allitude of one mile. Anesth. Analg. 48: 680 (1969)

83. Sudhir. K.G., SMIth, R.M.. HALl. J.E. \& HANSEN, D.D. Intraoperative atwakening for early recognition of possible neurologic sequelae during Harrington rod spinal fusion. Anesth. Analg. 55: $526(1976)$ 
84. Collman, A.J. \& Downing, J.W. Enflurane anesthesia for cesarean section. Anesthesiology 43: 354 (1975)

85. LATro. 1.P. \& WALORON. B.A. Anaesthesia for caesarean section. Br. J. A naesth. 49: 37। (1977).

86. WILSON, J. \& TURNIER. D.J. A wareness during caesarean section. Br. Med. J. 1: 280 (1969).

87. DUNDEE. J.W.. Bhown, S.S., Hamilton, R.C. \& MCDowELL. S.A. Analgesic supplementation of light general anaesthesia. Anaesthesia 24: 52 (1969).

88. BimAR. J. \& BeLLVILLE. J.W. Arousal reactions during anesthesia in man. Anesthesiology 47: 449 (1977).

89. Dubois. M. Savege. T.M. O'Carroll. T.M. \& Frank. M. General anaesthesia and changes on the cerebral function monitor. Anaesthesia 33: 157 (1978).
90. Ruder. C. \& Weinreich, A.l. Arousal during general anesthesia. Anesthesiology Review 3: 29 (June 1976).

91. JoHnstone, M. Digital vasodilatation: a sign of anaesthesia. Br. J. Anitesth. 46: 414 (1974)

92. TUNSTALL. M.E. Detecting wakefulness during general anaesthesia for ctesarean section. $\mathrm{Br}$. Med. J. 1: 1321 (1977).

93. DAS. B.B. Minimum blood concentration. at universal concept of anaesthetic potency. Br. J. Anaesth. 47: 881 (1975)

94. Brand, L., Mazzia, V.D.B.. Poznak, A.V. BurNS, J.J. M MARK. L.C. Lack of correlation between EEG effects and plasma concentrations of thiopentone. Br. J. Anaesth. 33: 92 (1961). 